\title{
Derived high reducing sugar and lignin colloid particles from corn stover
}

\author{
Wei Liu', Shengnan Zhuo ${ }^{2,3,4^{*}}$, Mengying $\mathrm{Si}^{2,3}$, Mengting Yuan ${ }^{2,3}$ and Yan Shi ${ }^{2,3}$
}

\begin{abstract}
Lignocellulosic biomass is considered as the largest potential candidate to develop alternative energy, such as biofuel, biomaterial. However, the efficient conversion of cellulose and practical utilization of lignin are great challenges for sustainable biorefinery. In this study, high reducing sugar yield and different size of lignin colloid particles (LCPs) were obtained via tetrahydrofuran-water $\left(\mathrm{THF}-\mathrm{H}_{2} \mathrm{O}\right.$ ) pretreatment of corn stover (CS). THF- $\mathrm{H}_{2} \mathrm{O}$ as a co-solvent, could efficiently dissolve lignin and retain cellulose. After the pretreatment, $640.87 \mathrm{mg} / \mathrm{g}$ of reducing sugar was produced, that was 6.66-fold higher than that of the untreated CS. Meanwhile, the pretreatment liquor could form spherical LCPs with different sizes ranged from 202 to $732 \mathrm{~nm}$ through self-assembly. We studied the optimal pretreatment condition to simultaneously realize the high reducing sugar yield $(588.4 \mathrm{mg} / \mathrm{g})$ and excellent LCPs preparation with average size of $243 \mathrm{~nm}$ was under $\mathrm{TH} 22\left(\mathrm{THF}-\mathrm{H}_{2} \mathrm{O}\right.$ pretreatment at $120^{\circ} \mathrm{C}$ for $2 \mathrm{~h}$ ). To further explore the formation of LCPs with different sizes. We studied the lignin structure changes of various conditions, concluded the size of LCPs was related to the lignin concentration and syringyl/guaiacyl $(\mathrm{S} / \mathrm{G})$ ratio. As the increase of the lignin concentration and $\mathrm{S} / \mathrm{G}$, the sizes of LCPs were increased. G-type lignin was easier to dissolve in the mild pretreatment supernatant, contributing to form smaller LCPs with a good dispersibility. In the severe condition, both of S and G-type lignin were dissolved due to the lignin depolymerization, formed the larger sphere particles. This work provides a novel perspective for the technical design of lignocellulosic biomass conversion.
\end{abstract}

Keywords: Corn stover, THF- $\mathrm{H}_{2} \mathrm{O}$ pretreatment, Reducing sugar, Lignin, Lignin colloid particles

\section{Introduction}

Lignocellulose, consisting of cellulose, hemicelluloses and lignin, is the most abundant biomass on earth [1]. 100 billion tons of lignocellulosic biomass are produced annually in the world, but less than $10 \%$ of them are utilized [2,3]. However, the burning of biomass will cause air pollution and climate problems [4]. For the decades, significant progresses have been made for the conversion of lignocellulosic biomass to energy and material used in environment remediation [5, 6]. As the component with the highest content in lignocellulosic biomass, cellulose plays an important role in pulp and paper, fuel

\footnotetext{
*Correspondence: zhsnan@126.com

${ }^{2}$ School of Metallurgy and Environment, Central South University, Changsha 410083, China

Full list of author information is available at the end of the article
}

ethanol, and other industries [7, 8]. Compared with cellulose and lignin, the branched structure and lower degree of polymerization property of hemicellulose made it easier to be degraded when subjected to heat pretreatment [9]. Therefore, it is preferentially separated from lignocellulosic raw materials and converted into industrial products, such as functional sugar, furfural, and other chemicals [10]. Most of the refining schemes focus on utilizing convertible celluloses and hemicelluloses, leaving lignin behind in the selective conversion processes [11, 12]. Lignin, together with cellulose and hemicellulose, constitutes a complex structure of lignocellulosic biomass with cross-linking heterogeneity [13]. Traditionally, lignin extraction is easy to destroy the original structure of lignin and form more inactive $\mathrm{C}-\mathrm{C}$ bonds, which is not conducive to the development and utilization of downstream industries [14]. Therefore, how to efficiently

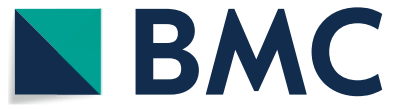

(c) The Author(s) 2020. This article is licensed under a Creative Commons Attribution 4.0 International License, which permits use, sharing, adaptation, distribution and reproduction in any medium or format, as long as you give appropriate credit to the original author(s) and the source, provide a link to the Creative Commons licence, and indicate if changes were made. The images or other third party material in this article are included in the article's Creative Commons licence, unless indicated otherwise in a credit line to the material. If material is not included in the article's Creative Commons licence and your intended use is not permitted by statutory regulation or exceeds the permitted use, you will need to obtain permission directly from the copyright holder. To view a copy of this licence, visit http://creativeco mmons.org/licenses/by/4.0/. The Creative Commons Public Domain Dedication waiver (http://creativecommons.org/publicdomain/ zero/1.0/) applies to the data made available in this article, unless otherwise stated in a credit line to the data. 
utilize lignin with low cost and aromatic nature to realize all components utilization has turned into a global conundrum in current biorefinery.

There is no doubt that achieving high content of sugar is the major goal in the advanced biorefinery process, for example, ethanol can be produced by the fermentation of sugars. In order to achieve the goal, removal of the outer lignin and retention of cellulose in lignocellulosic biomass has become the primary mission via pretreatment. Currently, a great many pretreatment strategies based on acid [15], alkali [16] and organic solvent [17] were employed to efficiently remove or solve lignin from lignocellulose, which improve the glucose releasing. Unfortunately, large amounts of lignin are wasted in the flushing way of pretreatment spent liquor. As we know, lignin as the natural aromatic compound with high carbon content, abundant bonds and functional groups, is a good precursor for the preparation of carbon-based materials including lignin fiber, activated carbon, carbon foam, and lignin nanomaterials $[16,18]$. Therefore, the utilization of lignin liquor is necessary.

According to the recent literatures, we knew lignin based nanoparticles has gained increasing interest, with the potential application in the fields of medicine, catalysis, water treatment adsorbents, and antimicrobial agents [19]. Lignin nanoparticles preparation usually uses lignin from the paper and pulping industry or biorefinery process, which need further chemical modification. For example, the uniform colloidal spheres were prepared via self-assembly with alkali lignin recovered from the pulping black liquor and chemically modified by acetylating [20]. Currently, lignin nanoparticles directly prepared with lignin produced from lignocellulose pretreatment were obtained [21, 22], which not only avoids lignin modification, but also realizes the utilization of waste lignin. However, the preparation of lignin nanoparticles and enzymatic hydrolysis of carbohydrates are always regarded as the different and independent processes. For example, when we want to obtain the high sugar conversion, we would use the high concentration of acid or alkali or organic under high temperature to remove much more lignin, thus, lignin nanoparticles might not be prepared directly. Otherwise, low content of lignin removal can not meet the accessibility of cellulase to cellulose, reducing the sugar yield [23]. Therefore, designing a method to simultaneously realize the formation of ligninbased materials from pretreatment liquid and the conversion of cellulose to sugar is significant and meaningful to the biorefinery of biomass.

In our previous studies, a new strategy involved a synergy of lignocelluloses pretreatment by $\mathrm{THF}-\mathrm{H}_{2} \mathrm{O}$ and bacterial strain to enhance enzymatic hydrolysis was developed $[24,25]$. The result showed $\mathrm{THF}-\mathrm{H}_{2} \mathrm{O}$ had a high lignin removal efficiency and retained a large amount of cellulose for sugar production. However, the pretreatment spent liquor was treated as wastewater after THF recovery. According to these literatures that lignin nanoparticles were prepared based on alkali lignin dissolved in THF [20, 26], we speculated the idea of synchronously achieve the high sugar yield and lignin nanoparticle using THF $-\mathrm{H}_{2} \mathrm{O}$ pretreatment is possible. It is worth noting that the shape and size of lignin nanoparticle were diverse. Many researchers reported the lignin nanoparticles with different shape and size were prepared from the different kinds of lignin (softwood kraft lignin, alkali lignin, Sigma-Aldrich kraft lignin) using different solvents (methanol, ethanol, DMF, THF) [26, 27]. It can be seen that, solvent, lignin type and experiment condition might be the effect factor on the particle size. Zhao also proposed that the solution structures of lignin is essential to prepare well-controlled lignin nanoparticles [28]. However, to date, though, as the above presented papers has proposed some causes of the particle size, little papers pay attention to the lignin nanoparticles formation combined with the biomass pretreatment and the role of lignin in the size variation of lignin particle.

In this work, the overall objective is to combine biomass pretreatment with lignin-based material preparation, we adopted the pretreatment pattern based on acid-catalyzed THF- $\mathrm{H}_{2} \mathrm{O}$ system, realizing the highly efficient enzymatic hydrolysis and formation of lignin colloid particles (LCPs) with appropriate size, elucidating the effect of lignin from pretreatment stream on the particle size. The specific objectives are: (1) study the enzymatic hydrolysis of CS under different pretreatment conditions (2) prepare the LCPs from the different pretreatment stream; and (3) elucidate the relationship between the lignin structure and the size of LCPs.

\section{Materials and methods \\ Materials and chemicals}

The corn stover (CS) was purchased from Jining, Shandong province, China. The CS after washing and drying was cut and crushed with a pulverizer, then sifted by 18 to 60 -mesh griddles and air-dried for $24 \mathrm{~h}$ at $50{ }^{\circ} \mathrm{C}$ before use. Tetrahydrofuran (THF, A.R.) was purchased from a commercial Shanghai Macklin Biochemical Co., Ltd. Concentrated sulfuric acid (98 wt \%) was purchased from ChengDu Chron Chemicals Co., Ltd. Other chemicals were purchased from a commercial source and used without any further purification. The whole research methodology was shown in Additional file 1: Figure S1.

\section{Biomass pretreatment}

The CS was weighed at the ration of $1: 20(\mathrm{~g} / \mathrm{ml})$ with the $\mathrm{THF} / \mathrm{H}_{2} \mathrm{O}(1: 1)$ solution. The mixture was placed in a 
$100 \mathrm{ml}$ of hydrothermal reactor. Then, the sulfuric acid $(0.5 \mathrm{wt} \%)$ was added as the catalyst. The hydrothermal reactor was put into the air drying oven after stirring. The temperature and time were $120^{\circ} \mathrm{C}$ and $150^{\circ} \mathrm{C}$ for $1 \mathrm{~h}$, $2 \mathrm{~h}$, and $4 \mathrm{~h}$, respectively. The reactor was quickly cooled down by flushing the water after pretreatments. Then, the solid residues and pretreatment solution were separated by vacuum filtration. The solution was collected and stored in a refrigerator $\left(4{ }^{\circ} \mathrm{C}\right)$. The solid residues were further filtrated by distilled water to remove THF until the $\mathrm{pH}$ was neutral, and then, dried at $50^{\circ} \mathrm{C}$ for $24 \mathrm{~h}$. The reaction condition was named as TH21, TH22, TH24, TH51, TH52, TH54, respectively.

\section{Enzymatic hydrolysis and composition analysis}

The enzymatic hydrolysis of dried $\mathrm{THF}-\mathrm{H}_{2} \mathrm{O}$ pretreated CS residues $(2.5 \%(\mathrm{w} / \mathrm{v}))$ was performed with Cellulase Cellic (CTec2, Novozymes) and citrate buffer $(0.05 \mathrm{M}, \mathrm{pH}$ 4.8) in the water bath shaker at $50^{\circ} \mathrm{C}, 150 \mathrm{rpm}$ for $72 \mathrm{~h}$. In addition, the tetracycline $(40 \mu \mathrm{g} / \mathrm{ml})$ and cycloheximide $(30 \mu \mathrm{g} / \mathrm{ml})$ are added into the enzymatic hydrolysis system to prevent microbial contamination. And then, the supernatant was took out and centrifuged to measure the reducing sugar with the DNS method [29]. The reducing sugar yield was calculated by the following equation.

$$
\mathrm{Y}=\frac{\mathrm{c} \times \mathrm{v}}{\mathrm{m}}
$$

where $\mathrm{Y}$ is the reducing sugar yield $(\mathrm{mg} / \mathrm{g})$, $\mathrm{c}$ is the sugar concentration $(\mathrm{g} / \mathrm{l}), \mathrm{v}$ is the system volume of enzymatic hydrolysis (ml), $\mathrm{m}$ is the mass of CS in the system of enzymatic hydrolysis (g).

All the experiments were done in triplicate. The composition including cellulose, hemicellulose, and lignin analysis was according to the previous literature [30]. All measurements were carried out in triplicate.

\section{Weight loss analysis}

The treated and untreated CS were washed three times, and dried in oven at $60^{\circ} \mathrm{C}$ for $12 \mathrm{~h}$. The weight was measured under dry condition. Then, the weight loss rate of CS was calculated with the different mass obtained before and after pretreatment [31]. All the experiments were done in triplicate.

\section{Morphology analysis}

The dried CS before and after pretreatments with different conditions were coated with gold and were detected with the scanning electron microscopy (SEM JSMIT300LA, JEOL, Japan) [32].

\section{Preparation of LCPs}

Pretreatment liquid from the biomass pretreatment under different conditions were transformed into different flasks. The excess of the deionized water was slowly added into each flask with constant magnetic stirring. Then, the colloid solutions containing LCPs from different pretreatment conditions were obtained as shown in Additional file 1: Figure S2. The prepared LCPs under various conditions was named as LCP21, LCP22, LCP24, LCP51, LCP52, LCP54, respectively.

\section{Characterization of LCPs}

The morphology of LCPs was observed with the field emission scanning electron microscope (FESEM, FEI Nova NanoSEM230, Czekh). The size and dispersity of particles were analyzed using a Nano-ZS (Malvern Instruments, UK). The absorption peak of LCPs in aqueous solutions was measured using a U-4100 Spectrophotometer (Thermo Scientific Inc., USA). The purified lignin directly extracted from the pretreatment liquid was used as the positive control. The extracted lignin was dissolved in the solution of THF and water at the ratio of 1:1. The chemical groups of LCPs were confirmed via a Nicolet IS10 Fourier Transform Infrared spectrometer (FTIR, Thermo Fisher, USA).

\section{Extraction and characterization of lignin}

In order to study the effect of lignin structure on the formation of LCPs, the lignin in the pretreatment liquid was extracted with the same method as the previous reported [30]. The extracted lignin samples were analyzed via a Bruker Avance $400 \mathrm{MHz}$ two-dimensional heteronuclear single quantum coherence nuclear magnetic resonance spectrometer (2D-HSQC-NMR, Billerica, MA, USA) to identify the change in structural units of lignin structure and investigate the cleavage of linkage bonds [33]. The chemical groups of lignin were analyzed through the FTIR [34]. The Waters Alliance gel permeation chromatography 1515 (Waters, USA) was used to analyze the molecular weight of lignin [35]. Before the sample tasting, lignin was first acetylated with acetic anhydride and pyridine, then methanol to stop reaction, and nitrogen purging, vacuum drying. Herein, lignin extracted from various pretreatment liquid LCPs was named as ligninTH21, lignin-TH22, lignin-TH24, lignin-TH51, ligninTH52, and lignin-TH54.

\section{Results and discussion} Efficient biomass pretreatment The release of reducing sugar

Generally, pretreatment is the primary step for the utilization of biomass to sugars, ethanol or other compounds 
[36]. The sugar yields after enzymatic digestibility is the major criteria for determining the efficiency of pretreatments. Enzymatic hydrolysis of CS under all pretreatment conditions was carried out and the corresponding reducing sugar yield was investigated (Fig. 1). All the reducing sugar yields produced from CS that pretreated by THF- $\mathrm{H}_{2} \mathrm{O}$ system under different conditions were higher than that $(84.7 \mathrm{mg} / \mathrm{g})$ of the untreated [24]. They are $301.23 \mathrm{mg} / \mathrm{g}, 588.45 \mathrm{mg} / \mathrm{g}, 619.62 \mathrm{mg} / \mathrm{g}$ of TH21, TH22, TH24 and $579.83 \mathrm{mg} / \mathrm{g}, 640.87 \mathrm{mg} / \mathrm{g}$ and $613.9 \mathrm{mg} / \mathrm{g}$ of TH51, TH52, TH54. The maximum yield of $640.87 \mathrm{mg} / \mathrm{g}$ was obtained after pretreatment under TH52, which was highly competitive compared with others in previous works $[15,37]$. In addition, the yield of the reducing sugar increased from $301.23 \mathrm{mg} / \mathrm{g}$ (TH21) to $619.62 \mathrm{mg} / \mathrm{g}$ (TH24) with the prolongation of reaction time under $120{ }^{\circ} \mathrm{C}$, which was attributed to the breakdown of the biomass recalcitrance structure. A large amount of lignin was dissolved by THF- $\mathrm{H}_{2} \mathrm{O}$, and the internal cellulose was gradually exposed, which promoted the accessibility of the cellulase to the substrate [25]. In general, the reducing sugar yield of biomass pretreated by THF- $\mathrm{H}_{2} \mathrm{O}$ increases with the increase of the pretreated temperature and time [25]. However, it was surprised to observe that the reducing sugar yield of CS pretreated at $150{ }^{\circ} \mathrm{C}$ increased from $579.83 \mathrm{mg} / \mathrm{g}$ (TH51) to $640.87 \mathrm{mg} / \mathrm{g}$ (TH52) first, and then decreased to $613.9 \mathrm{mg} / \mathrm{g}$ (TH54) with the increase of the pretreated time. Although enzymatic digestion was significantly improved due to lignin removal from $\mathrm{CS}$ by $\mathrm{THF}-\mathrm{H}_{2} \mathrm{O}$ under low temperature, there is still lignin remained in the pretreated CS, may play a physical adsorption role of nonproductive binding with cellulase in the enzymatic hydrolysis $[38,39]$. This lignin residue can be further dissolved and removed from

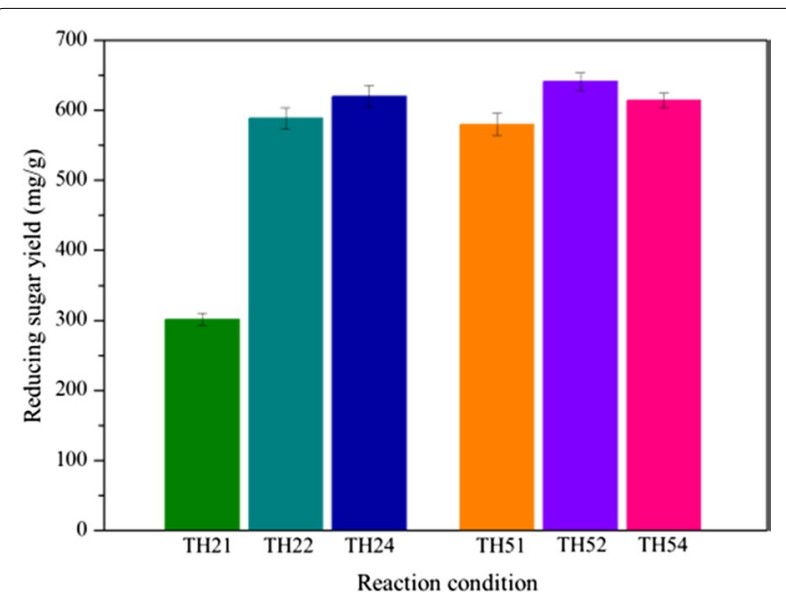

Fig. 1 Reducing sugar yield of corn stover pretreatment under different conditions cell wall structure under severe condition [40], which resulted that the reducing sugar yields under $150{ }^{\circ} \mathrm{C}$ are higher than that under $120{ }^{\circ} \mathrm{C}$ with similar pretreated times. Although most of lignin has been removed from CS under TH54, the reducing sugar yield was not increased compared to that of TH52. In general, the more lignin removed under severe condition, the more internal cellulose exposed to the outside, which was benefit to the enzymatic hydrolysis of cellulose. For this phenomenon, we speculated some of the exposed cellulose might be attacked, which resulted in a decrease in the amount of degradable cellulose. The conceivable proof will be discussed and proved depending on the SEM analysis.

\section{Morphology change of CS}

The purpose of pretreatment is not only to remove lignin on the surface of biomass as much as possible but also to maximize the retention of cellulose to obtain a high yield of the reducing sugar. The efficiency of biomass pretreatment is closely related to the change of its structure. To deep understand the reducing sugar production from pretreated CS, the morphology changes of CS before and after pretreatment were analyzed. The surface of the untreated CS (Fig. 2a) is smooth and rigid, covered with a large amount of lignin which is the physical barrier for cellulase [41]. In contrast, the surface of CS pretreated under TH21 was changed (Fig. 2b). Some lignin droplets were formed and deposited on the surface of the pretreated residues, which was similar to the phenomenon that was found in dilute sulphuric acid pretreatment of lignocellulosic biomass [15]. The formation of lignin droplets was caused by the acidic environment created by adding sulfuric acid as a catalyst in $\mathrm{THF}-\mathrm{H}_{2} \mathrm{O}$ system. However, the lignin droplets remained on the surface of CS hindered the enzymatic hydrolysis, resulting in the low yield of the reducing sugar under TH21. In contrast, the morphology of CS pretreated under the other five reaction conditions has undergone tremendous changes. For example, the CS pretreated by TH22 was split and the cellulose fiber was observed (Fig. 2c). The CS was seriously deformed after TH24 pretreatment (Fig. 2d), indicating that the structure of the CS was fragile and collapsed [42]; No matter TH22 or TH24, the integrated structure of CS has been destroyed, the most importantly, cellulose appeared. It means that the enzymatic hydrolysis was easier than the CS covering with rigid lignin and lignin droplets. For TH51, CS was also cracked, showing the internal cellulose structure (Fig. 2e). Moreover, the fiber bundles can be seen in TH52 pretreated CS (Fig. 2f), which significantly increased the accessibility of cellulose to the enzyme, contributing to the highest reducing sugar yield. With the aggravation of reaction conditions, TH54 emerged a slurry structure (Fig. $2 \mathrm{~g}$ ), it was worth noting 

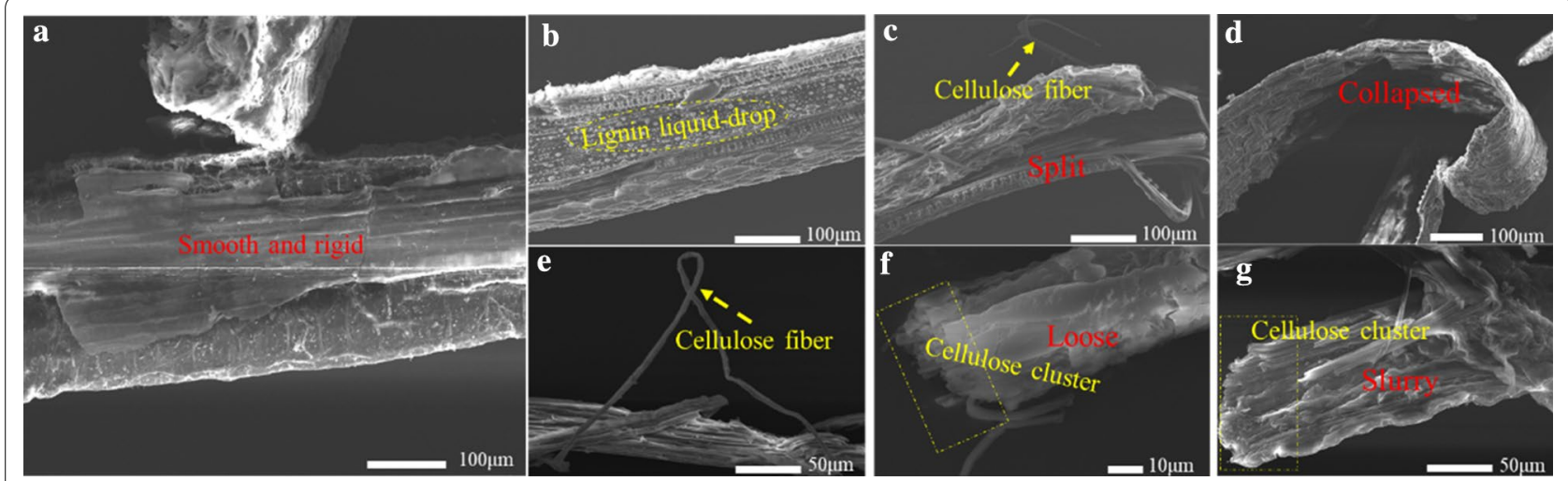

Fig. 2 SEM of corn stover pretreatment under different condition (a un-treatment, b TH21, c TH22, d TH24, e TH51, f TH52, g TH54)

that although it retained the cellulose, its structure was not as loose as the TH52, which explained the cause of reducing sugar yield decrease.

\section{Component change and mass loss of the CS}

The change of CS structure after pretreatment will inevitably lead to the change of component and the loss of mass. Therefore, the analysis of component changes and mass loss before and after pretreatment was conducted.

The CS used in this study consists of $34.9 \%$ of cellulose, $38.5 \%$ of hemicellulose, $13.9 \%$ of lignin, and $12.7 \%$ of other non-organic and organic components [24]. As shown in Additional file 1: Figure S3, compared with the untreated CS, lignin and hemicellulose in the solid residual decreased from 13.87 to $10.02 \%$ and from 38.36 to $13.8 \%$, respectively, with the increase of reaction time at $120{ }^{\circ} \mathrm{C}$. It indicated that lignin and hemicellulose is continuously dissolved in $\mathrm{THF}-\mathrm{H}_{2} \mathrm{O}$ system. The removal of lignin and hemicellulose also gradually increased at $150{ }^{\circ} \mathrm{C}$. The content of lignin and hemicellulose in CS residue after pretreatment decreased from 12.8 to $6.59 \%$ and from 30.68 to $10.21 \%$, respectively. Due to the removal of lignin, the content of cellulose was correspondingly increased. It changed from 47.71 (TH21) to $55.68 \%$ (TH24) and from 52.99 (TH51) to $71.71 \%$ (TH54), respectively. However, the highest cellulose content of $76.11 \%$ occurred in the TH52, which was best to the production of reducing sugar from TH52, the result was in line with the reducing sugar yield.

The mass loss of treated CS was all increase from TH21 to TH24 and TH51 to TH54. The data were $36.14 \%$, $50.54 \%, 52.00 \%$ and $48.11 \%, 55.11 \%, 67.46 \%$ under $120^{\circ} \mathrm{C}$ and $150{ }^{\circ} \mathrm{C}$, respectively (Fig. 3). The mass loss of CS under TH21 was the minimum of $36.14 \%$. In addition, based on the analysis of the reducing sugar yield and the morphology of the CS, it can be inferred that the mass loss of CS is mainly attributed by the removal of a small

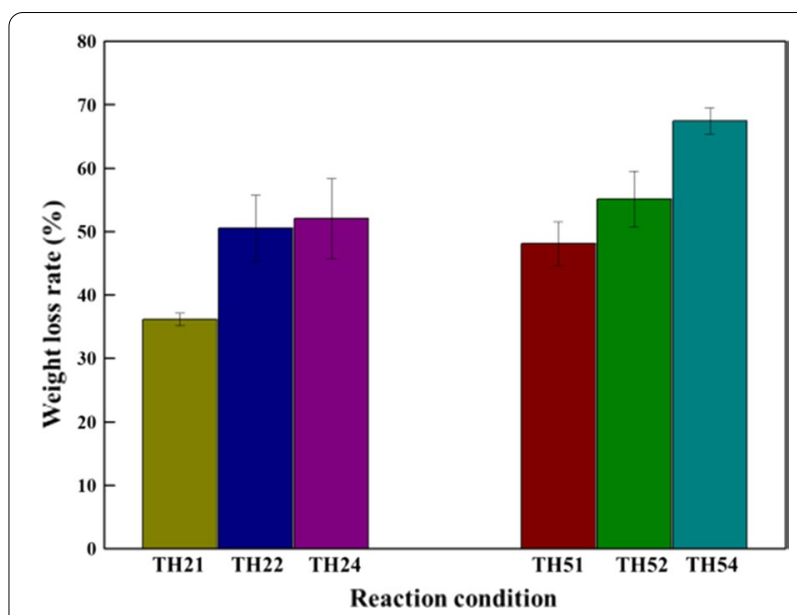

Fig. 3 Weight loss of corn stover by the pretreatment under different conditions

amount of lignin and other components like hemicellulose by $\mathrm{THF}-\mathrm{H}_{2} \mathrm{O}$ co-solvent system [42]. Most of the lignin formed droplets and deposited on the surface of the CS residue. Compared with TH21, the mass losses of $\mathrm{TH} 22$ and $\mathrm{TH} 24$ were markedly to $50.5 \%$ and $52 \%$ respectively, which were resulted from most of the hemicellulose and lignin removal (Additional file 1: Figure S3). Similarly, with the increase of reaction time, the more lignin was removed, the increasing mass loss was observed at $150{ }^{\circ} \mathrm{C}$. Moreover, under TH54, some cellulose was degraded after lignin removal, which resulted in the mass loss reach to $67.46 \%$, and it was unacceptable in the practical application.

Therefore, in order to maximize the yield of the reducing sugar from biomass, it is very important to optimize the pretreatment conditions. Compared with the other THF pretreatment $[43,44]$, in our work, the pretreatment method adopted the lower temperature $\left(120^{\circ} \mathrm{C}\right)$, and we also obtained the satisfying result. The most important 
reason we selected $\mathrm{THF}-\mathrm{H}_{2} \mathrm{O}$ co-solvent as the pretreatment solvent is that the pretreatment liquid can be directly to prepare lignin nanoparticles $[20,26]$ rather than discarded.

\section{Formation of LCPs}

The current utilization of biomass resources is involved in the utilization of both cellulose and lignin due to its unique structure. Therefore, in addition to the high reducing sugar yield obtained from CS by THF- $\mathrm{H}_{2} \mathrm{O}$ pretreatment, we directly used the pretreatment supernatant to prepare LCPs via introducing water into it without other chemical modification, which realized the efficient utilization of lignin in biomass. Different concentrations of colloid solution were formed based on the supernatants obtain from pretreatment under six different reaction conditions (Additional file 1: Figure S2). To understand the characteristics of the colloid solution, we adopted SEM to observe the morphology of LCPs, nano size analyzer to get information of particle size distribution statistics, Uv-vis to measure the concentration of colloid solution, and FTIR to analyze the functional groups of lignin particles.

\section{Morphology and Size analysis of $L C P$ s}

All the prepared LCPs were spherical and rich, concatenate (Fig. 4). The phenomenon is similar to other researches [27, 45], resulting from the electrostatic interaction. The particle size increased with the increase of the reaction time under the temperatures of $120^{\circ} \mathrm{C}$ and $150^{\circ} \mathrm{C}$. LCP21 were very small and had a small number. The particle size mainly distributes between 164 and $295 \mathrm{~nm}$, and the average particle size was $202 \mathrm{~nm}$. The size distribution of LCP22 was 164-342 nm, which was a little bigger than that of LCP21. Its average particle size was $243 \mathrm{~nm}$ and the dispersion of particles was better than that of LCP21. LCP24 had a particle size distribution of 255-615 $\mathrm{nm}$ with the average particle size of $385 \mathrm{~nm}$. Besides, it could be observed that the minimum particle size of LCP24 is larger than the average particle size of LCP21 and LCP22. Moreover, the particle sizes of LCP51, LCP52, and LCP54 were gradually increased. The corresponding particle sizes were 190-342, 459-712, 615-955 $\mathrm{nm}$ with the average particle sizes of 259, 547 and $732 \mathrm{~nm}$, respectively. These results indicated that the lignin particle size gradually increased with the increase of reaction intensity. In addition, some particles of LCP54 even reached about $\sim 1000 \mathrm{~nm}$. The explanation for this result might be related to the lignin structure dissolved in different pretreatment solution. In addition, the LCPs prepared in this work was comparative to the other lignin particles with various shapes and sizes prepared by different methods (Additional file 1: Table S1).
To confirm the different particle size of LCPs was caused by the structure of lignin, we next adopted the UV wavelength scanning to observe the if the formation interaction changes.

\section{Uv-vis analysis of $L C P S$}

Uv-vis was used to compare the lignin in the pretreatment solution with the corresponding LCPs to analyze the formation of LCPs. Previous studies have discussed that the LCPs are formed by the $\pi-\pi$ interaction of orbitals of non-chemical bonds between aromatic rings in lignin molecule $[20,46]$. Before and after the formation of colloid particles, the adsorption peak would shift under the $\pi-\pi$ interaction [46]. As displayed in Fig. 5, the absorption peak of typical benzene compounds $(\sim 280 \mathrm{~nm})$ was observed in the lignin and LCPs solution, suggesting the aromatic ring structure of lignin has not destroyed in the process of LCPs formation. It was consistent with the conclusion that $\pi-\pi$ interaction in lignin caused the hydrophobic effect which brought about the formation of lignin colloid in solution [20]. The different shifts of maximum $\lambda$ at $\sim 280 \mathrm{~nm}$ indicated the weakening or strengthening of aromatic groups in $\pi$-stacking from lignin [20]. Lignin consist of three units including guaiacyl, syringyl, and phydroxyphenyl, their aromatic structure is different [19]. Therefore, the variation in $\pi$-stacking may be attributed to the different aromatic structures of lignin dissolved in the pretreatment liquid. Thus, we will conduct the effect research of lignin structure on LCPs.

Moreover, we found the LCP24, LCP52, and LCP54 had a higher absorption peak at maximum $\lambda$, which were related to their high concentration that can be seen in Additional file 1: Figure S2. The higher concentration of LCPs depended on the increase in lignin dissolution with the increase of pretreatment reaction degree.

\section{FTIR analysis of $L C P S$}

The structural properties of materials determine their application values. Therefore, FTIR was used to characterize the functional groups of LCPs. As shown in Fig. 6, the abundant functional groups were visually observed in the LCPs prepared from pretreatment solutions at $120^{\circ} \mathrm{C}$ and $150{ }^{\circ} \mathrm{C}$. The broad absorption peak at $3400 \mathrm{~cm}^{-1}$ and the band at $\sim 1379 \mathrm{~cm}^{-1}$ represent $-\mathrm{OH}$ stretching of phenolic and aliphatic moieties. The bands at $2918 \mathrm{~cm}^{-1}$ and $2849 \mathrm{~cm}^{-1}$ represent $\mathrm{C}-\mathrm{H}$ stretching [47]. Aromatic skeleton stretching occurs at $\sim 1600 \mathrm{~cm}^{-1}, \sim 1515 \mathrm{~cm}^{-1}$ , $1426 \mathrm{~cm}^{-1}$. The $\mathrm{C}=\mathrm{O}$ stretching in guaiacyl $(\mathrm{G})$ unit appeared at $\sim 1267 \mathrm{~cm}^{-1}$ [48]. All these location peaks suggested that there is no significant change in the aromatic structure of lignin in the process of LCPs formation; and the particle surface modified with high phenolic 

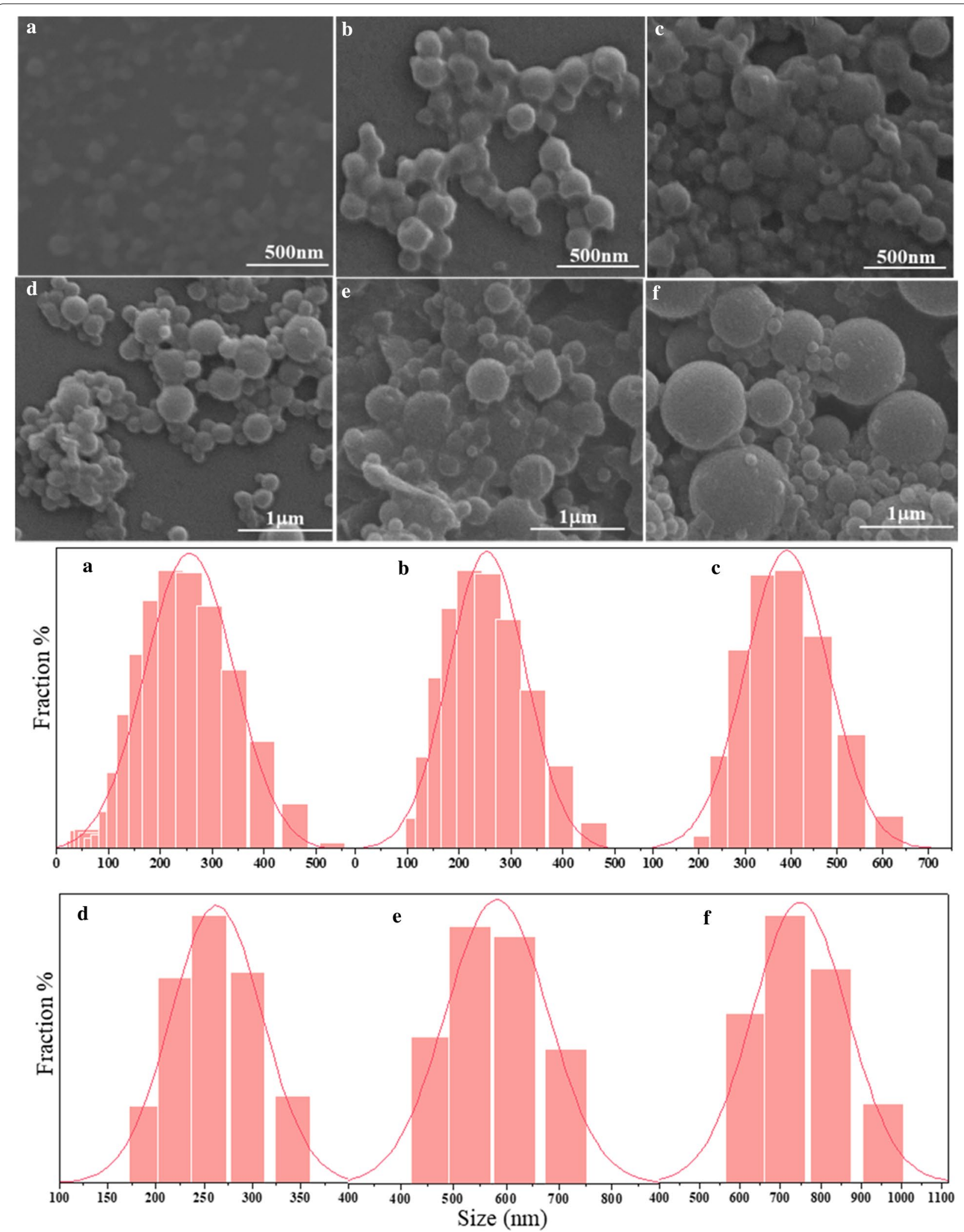

Fig. 4 Size Distribution and FESEM of $L C P s$ prepared from different pretreatment liquid. a $L C P 21$, b $L C P 22, \mathbf{c} L C P 24$, d $L C P 51$, e $L C P 52$, $\mathbf{f} L C P 54$ 

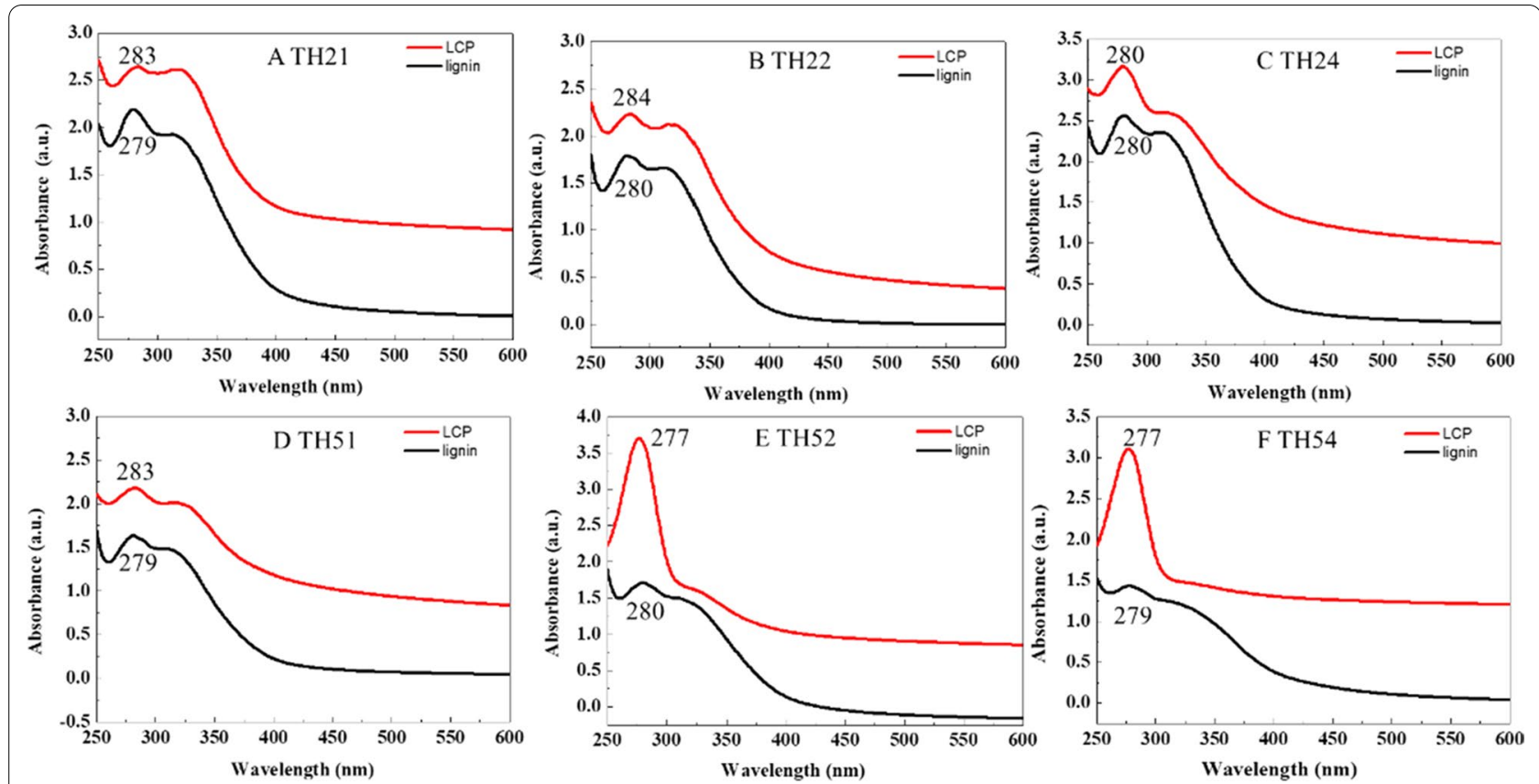

Fig. 5 Uv-vis spectra comparison of lignin and LCPs from the pretreatment liquor under different conditions
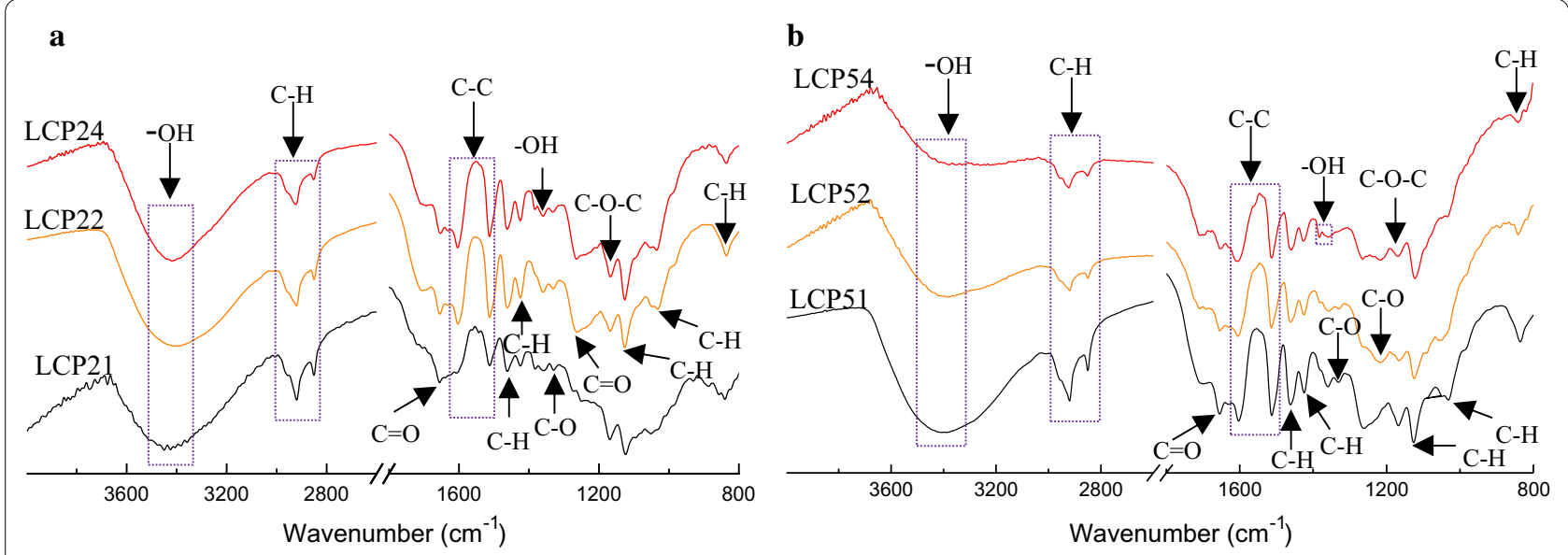

Fig. 6 FTIR spectra of LCPs prepared from different pretreatment liquid

hydroxyl and carboxyl functional groups is good for the solubility and stability of LCPs. In addition, LCPs have extra function groups of $\mathrm{C}=\mathrm{O}\left(\right.$ at $\sim 1330 \mathrm{~cm}^{-1}$ and $\sim 1265 \mathrm{~cm}^{-1}$ ) and $\mathrm{C}-\mathrm{O}-\mathrm{C}$ (at $\sim 1165 \mathrm{~cm}^{-1}$ ) compared with the lignin [49]. In recent years, the LCPs with plenty of functional groups have been reported to play an important role in the adsorption materials applied in the environment field and other composite materials preparation for biomedical or cosmetic fields [18, 50]. Therefore, the LCPs in our study have the potential to be applied in these fields.

\section{Influence of lignin on the LCPs}

Spherical LCPs with different sizes were prepared in different pretreatment solution. The formation of LCPs is closely related to the structure and concentration of dissolved lignin [28], therefore, we not only performed component analysis, but also extracted the lignin from the liquid and analyzed their molecular weight and structural changes by GPC, FTIR, and 2D-HSQC-NMR to elucidate the impact mechanism of lignin on the formation of LCPs. 


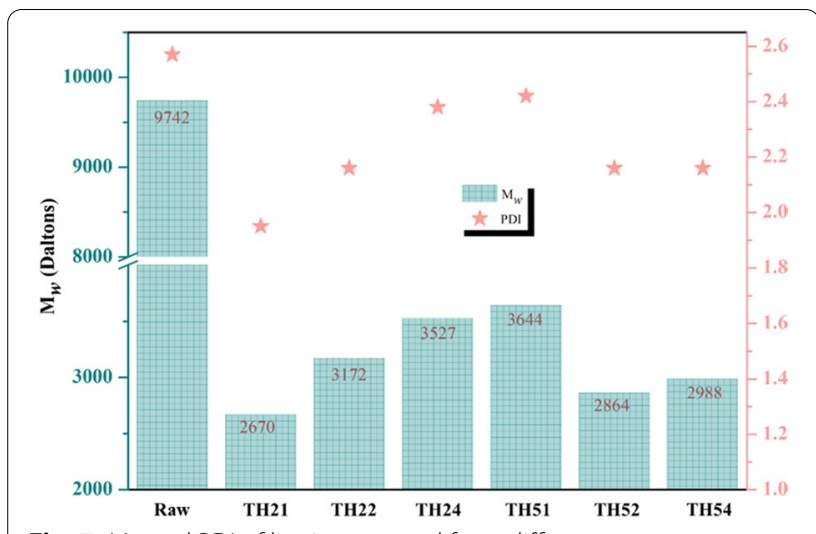

Fig. $7 M_{w}$ and PDI of lignin extracted from different pretreatments

\section{GPC analysis}

The analysis of the changes in lignin molecular weight through GPC can be used to characterize the degree of lignin polymerization after $\mathrm{THF}-\mathrm{H}_{2} \mathrm{O}$ pretreatment. The deconstruction of the macromolecular lignin can be characterized via three indexes including weightaverage molecular weight $\left(\mathrm{M}_{\mathrm{w}}\right)$, number-average molecular weight $\left(\mathrm{M}_{\mathrm{n}}\right)$, and dispersive poly-dispersity (PDI).

Figure 7 displayed the $M_{w}$ and PDI of lignin extracted from different pretreatment solutions. The lignin extracted from the raw CS had the highest $M_{w}$ (9742 Da) and PDI (2.57), indicating the high polymerizability and complexity of lignin in CS [51]. Compared with the raw lignin, the $M_{w}$ of lignins in the pretreatment solution drastically decreased. The $\mathrm{M}_{\mathrm{w}}$ and PDI increased from 2670 and 1.95 of lignin-TH21 to 3527 and 2.38 of lignin-TH24, respectively. In addition, the highest $\mathrm{M}_{\mathrm{w}}$ (3644) and PDI (2.42) were obtained in lignin-TH51, then, decrease to 2988 and 2.16 of ligninTH54. Combined with the above "The release of reducing sugar" section analysis, it can be inferred that lignin with small molecule weight was initially dissolved by THF $-\mathrm{H}_{2} \mathrm{O}$ under $\mathrm{TH} 21$, and the molecular weight distribution (MWD) is narrow; Then, more and more lignin with large molecule weight was dissolved, the corresponding MWD gradually widened. The molecule weight of dissolved lignin from TH51 reached to the maximum. Next, the dissolved lignin started to depolymerize as the reaction condition continued to intensify. However, some of depolymerized lignin might repolymerize under severe condition [52, 53]. Therefore, the $\mathrm{M}_{\mathrm{w}}$ of lignin-TH54 was a little higher than that from lignin-TH52. It seems to explain the increased size of LCPs was because of the increase of $M_{w}$ from lignin-TH21 to lignin-TH24. However, it was not suitable to the trend from LCP-TH51 to LCP-TH54. Thus, it is necessary to further analyze the specific changes of lignin structure and ensure the form of lignin units in THF $-\mathrm{H}_{2} \mathrm{O}$.

\section{FTIR analysis}

Based on the reducing sugar yield and the characteristics of the prepared LCPs, the lignin-TH22 and lignin-TH52 were selected for FTIR and 2D-HSQC-NMR analysis to further investigate the effect of lignin structure on the size of LCPs.

Obviously, FTIR spectra (Fig. 8) showed that most of the characteristic peaks of lignin-TH22 and lignin-TH52 still remained in these two samples $[54,55]$. The peaks at $1617 \mathrm{~cm}^{-1}, 1513 \mathrm{~cm}^{-1}$, and $1426 \mathrm{~cm}^{-1}$ were related to the vibration of aromatic ring skeleton, and the peak at $1462 \mathrm{~cm}^{-1}$ represented the C-H deformation of aromatic ring skeleton. These peaks indicated the existence of benzene structure in lignin-TH22 and lignin-TH52 [24]. However, compared with lignin-TH22, the peak at $1320 \mathrm{~cm}^{-1}$ which represented $\mathrm{C}=\mathrm{O}$ stretching in syringyl (S) derivatives disappeared in lignin-TH52. In addition, the $\mathrm{G}$ ring breathing with $\mathrm{C}=\mathrm{O}$ stretching $\left(\right.$ at $1270 \mathrm{~cm}^{-1}$ ) significantly decrease from lignin-TH52 [56]. Moreover, the peak at $1164 \mathrm{~cm}^{-1}$ which was attributed to the $\mathrm{C}-\mathrm{O}-\mathrm{C}$ vibration only remained in lignin-TH22. The peak at $1227 \mathrm{~cm}^{-1}$ associated with $\mathrm{C}-\mathrm{C}, \mathrm{C}-\mathrm{O}$, and $\mathrm{C}=\mathrm{O}$ stretching only appeared in lignin-TH52. These changes might be caused by the break of linkage bonds due to the severe pretreatment. The destruction of linkages resulted in the changes of lignin structure units (i.e. $\mathrm{S}$ and G), which might be the key factors to explain the formation of LCPs with different size. In order to further confirm the speculation, we adopted the 2D-HSQC-NMR analysis to illustrate the structural changes of lignin.

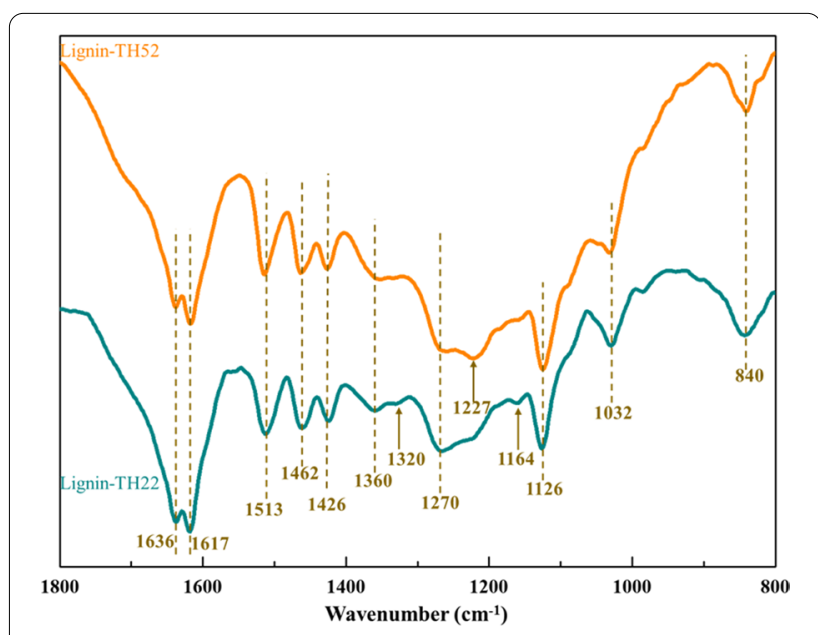

Fig. 8 FTIR spectra of lignin extracted from $\mathrm{TH} 22$ and $\mathrm{TH} 52$ 


\section{D-HSQC-NMR analysis}

Generally, the lignin consists of three basic units $(\mathrm{S}, \mathrm{G}$ and $\mathrm{p}$-hydroxyphenyl $(\mathrm{H})$ ) and linked by $\beta-\mathrm{O}-4, \beta-\beta, \beta-5$ etc. [57]. All these signals can be reflected through the 2D-NMR spectra. The signal information of side chain region $\left(\delta_{\mathrm{C}} / \delta_{\mathrm{H}} 50-90 / 2.5-6.0\right)$ and aromatic region $\left(\delta_{\mathrm{C}} / \delta_{\mathrm{H}}\right.$ $100-135 / 5.5-8.5)$ of lignin-TH22 and lignin-TH52 was displayed in Fig. 9. And the main cross-signals of lignin related to HSQC spectra were listed in Additional file 1: Table S2.

In the side chain region, the signals of $\beta-O-4$ and $\beta-5$ bonds in lignin-TH22 is stronger than that of lignin$\mathrm{TH} 52$, indicating the lignin in the dissolved process was severely destroyed under TH52. In the aromatic region, the S-type and G-type of lignin-TH52 significantly decreased, and the signals of $\mathrm{H}$-type lignin completely disappeared. In contrast, the signals of all three basic lignin units (S, G and H-type) remained in lignin-TH22. Specifically, the G-type lignin-TH22 were much higher than that of lignin-TH52. It is suggested that THF- $\mathrm{H}_{2} \mathrm{O}$ can dissolve the three types of lignin initially, and $\mathrm{H}$ lignin was not destroyed in lignin-TH22. However, the portion of G-type lignin was depolymerized in ligninTH52. It is worth noting that it is easier for high content of G-type or low S/G lignin to form small size LCPs [21]. Therefore, in order to achieve the preparation of LCPs with smaller particle size, the reaction solvent must have the ability to dissolve more G-type lignin or control the deconstruction of G-type lignin via the suitable reaction environment. In our work, the size of LCP22 was lower than that of LCP52, suggesting the THF $-\mathrm{H}_{2} \mathrm{O}$ solvent under TH22 efficiently dissolved more types of lignin, the G-type lignin under TH52 was not as much as TH22 due to its depolymerization.

\section{The concentration of lignin in the supernatant}

The concentration of lignin depends on the amount of lignin removed after pretreatment. Lignin removal was increased with the increase of the reaction intensity, what was demonstrated by the component change (Additional file 1: Figure S3). Component analysis showed that the order of lignin content removed from the CS was TH5 $4>\mathrm{TH} 52>\mathrm{TH} 24>\mathrm{TH} 52>\mathrm{TH} 22>\mathrm{TH} 21$. The highest concentration was obtained under TH54. Besides, lignin

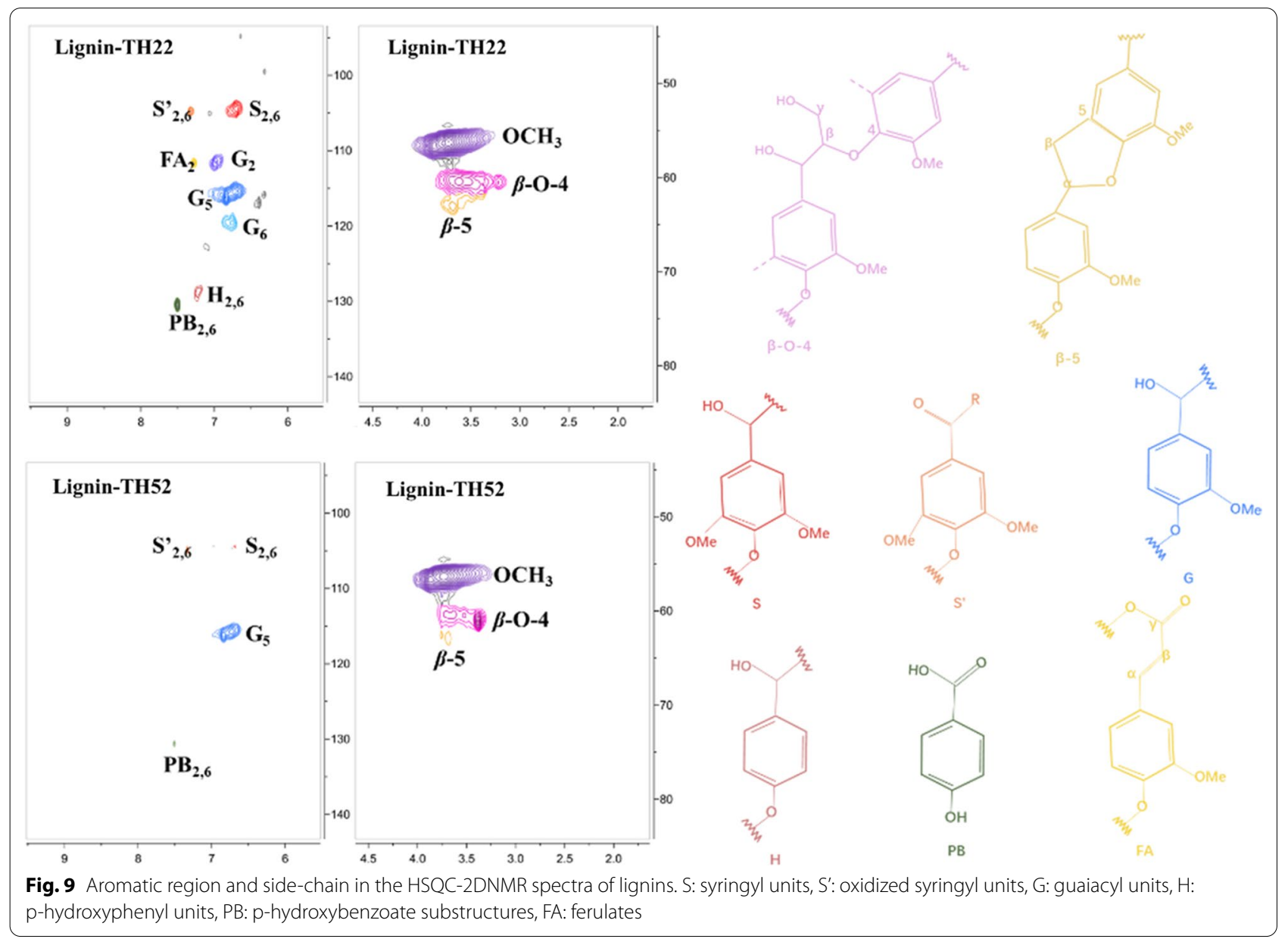


concentration could be directly observed from the color and turbidity of the LCPs solution (Additional file 1: Figure S2). Size analysis of LCPs indicated that the change of particle size is consistent with the change of lignin concentration. And the largest size of LCPs was obtained under TH54, which may be because the gather between particles. At the same volume, the particle size in the solution with low concentration of lignin is smaller due to the less content of lignin.

Lignin from the pretreatment solution under TH52 cannot form good LCPs even if the maximum yield of reducing sugar was obtained. However, pretreatment under TH22 realize the preparation of LCPs with good properties and high reducing sugar yield. Therefore, the pretreatment under $\mathrm{TH} 22$ was more practical in the actual biorefinery. The schematic of the sugar conversion and the mechanism of the formation of LCPs was fabricated as shown in Fig. 10. This strategy provides a practical guiding significance for the design of biomass pretreatment and the preparation of LCPs.

\section{Conclusions}

In this study, efficient reducing sugar and lignin colloid particles were simultaneously obtained based on the CS pretreatment by THF $-\mathrm{H}_{2} \mathrm{O}$ with the acid catalytic system. Under the optimum pretreatment condition of TH22, a high reducing sugar yield of $588.45 \mathrm{mg} / \mathrm{g}$ and LCPs with good dispersibility and average particle size of $243 \mathrm{~nm}$ were obtained. Lignin removal and structure destruction of CS promoted the conversion of cellulose to sugar yield. More G-type lignin was dissolved in THF $-\mathrm{H}_{2} \mathrm{O}$ solution under TH22, as the basic solution to form the LCPs with appropriate sizes. In contrast, due to the depolymerization of lignin under the severe condition, leading to the decrease of G-type content or the increase of $S / G$, which resulted in the formation of larger particle that limited its application in future. Our work provides an advanced design idea for biorefinery in material preparation and energy utilization through the elucidation of influence of lignin structure on lignin-based material formation. It was meaningful

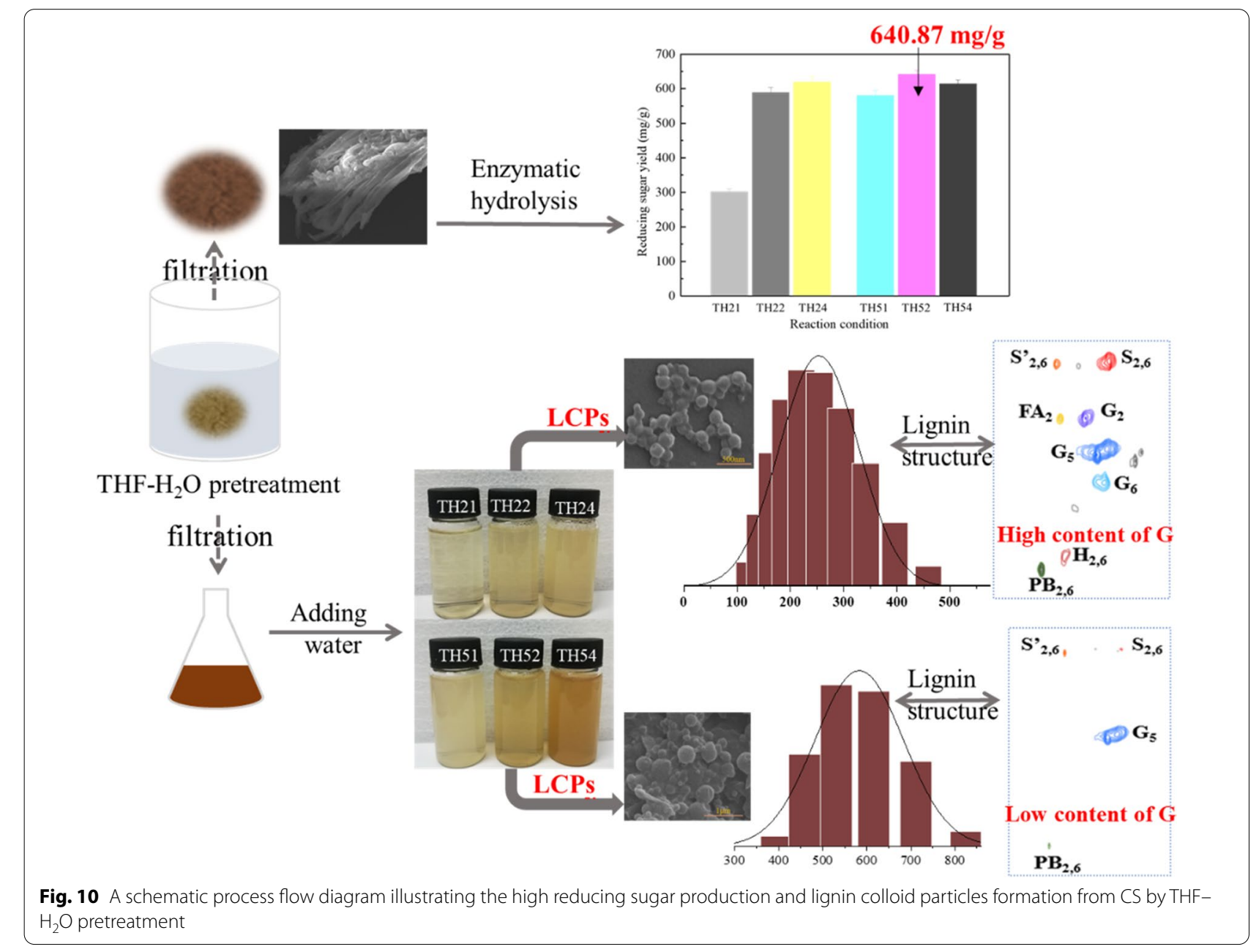


to the development of cellulose conversion and the utilization of lignin. In the future, we will pay attention to the application of LCPs, hoping to discover its application potential in environment, medicine, biology and so on.

\section{Supplementary Information}

The online version contains supplementary material available at https://doi. org/10.1186/s13065-020-00725-y.

Additional file 1: Figure S1. Flowchart of the whole study process. Figure S2. Lignin colloid solution from different pretreatment condition. Figure S3. Chemical composition of corn stover before and after the pretreatment. Table S1. The lignin nanoparticles prepared from various methods. Table S2. Assignment of Main Lignin ${ }^{13} \mathrm{C}-{ }^{1} \mathrm{H}$ Cross-Signals in the HSQC spectra of the lignin fractions.

\section{Abbreviations}

CS: Corn stover; THF- $\mathrm{H}_{2} \mathrm{O}$ : Tetrahydrofuran-water; G: Guaiacyl; S: Syringyl; $\mathrm{H}$ : -Hydroxyphenyl; LCPs: Lignin colloid particles; TH21: $120^{\circ} \mathrm{C}$ for $1 \mathrm{~h}$; TH22: $120^{\circ} \mathrm{C}$ for $2 \mathrm{~h} ; \mathrm{TH} 24: 120^{\circ} \mathrm{C}$ for $4 \mathrm{~h}$; TH51: $150{ }^{\circ} \mathrm{C}$ for $1 \mathrm{~h}$; TH52: $150{ }^{\circ} \mathrm{C}$ for $2 \mathrm{~h}$; TH54: $150^{\circ} \mathrm{C}$ for $4 \mathrm{~h}$; LCPxx: Colloid particles prepared from THxx pretreatmentnumber-average molecular weight; PDI: Poly-dispersity; Mw: Weight-average molecular weight; Mn: Number-average molecular weight; MWD: Molecular weight distribution; FESEM: Field emission scanning electron microscope; FTIR: Fourier Transform Infrared spectrometer; Uv-vis: Ultraviolet visible spectroscopy; GPC: Gel permeation chromatography; HSQC-NMR: Heteronuclear single quantum coherence nuclear magnetic resonance.

\section{Acknowledgements}

The authors thank the Chinese National Engineering Research Center for Control \& Treatment of Heavy Metal Pollution for proving the instruments tests.

\section{Authors' contributions}

WL designed, guided, and supported the experiment. SNZ performed the experiments and analyzed the data, wrote the original draft of the manuscript. MYS conducted the writing idea of manuscript, MTY repeated the enzymatic hydrolysis experiment. YS conducted the project and reviewed the manuscript. All authors read and approved the final manuscript.

\section{Funding}

This work was supported from the Program of Jilin Provincial Education Department (TJKH20170438KJ) and Key R\&D Program of Hunan Province (2018SK2044).

\section{Availability of data and materials}

All data generated or analyzed during this study are included in this published article.

\section{Ethics approval and consent to participate}

Not applicable.

\section{Consent for publication}

Not applicable.

\section{Competing interests}

The authors declare that they have no competing interests.

\section{Author details}

${ }^{1}$ School of Life Science, Tonghua Normal University, Tonghua 134000, China.

2 School of Metallurgy and Environment, Central South University, Changsha 410083, China. ${ }^{3}$ Chinese National Engineering Research Center for Control \& Treatment of Heavy Metal Pollution, Changsha 410083, China. ${ }^{4}$ School of Environment, Harbin Institute of Technology, Harbin 150090, China.
Received: 7 July 2020 Accepted: 1 December 2020

Published online: 10 December 2020

\section{References}

1. George WH, Iborra S, Corma A (2006) Synthesis of transportation fuels from biomass: chemistry, catalysts, and engineering. ChemRev. 106:4044-4098. https://doi.org/10.1021/cr068360d

2. Xiao Q, Chen W, Tian D, Shen F, Hu J, Lulu L, Yongmei Z, Gang Y, Deng S (2020) Integrating the bottom ash residue from biomass power generation into anaerobic digestion to improve biogas production from lignocellulosic biomass. Energy Fuel. 34:1101-1110. https://doi.org/10.1021/ acs.energyfuels.9b01898

3. Raj T, Kapoor M, Gaur R, Christopher J, Lamba B, Tuli DK, Kumar R (2015) Physical and chemical characterization of various indian agriculture residues for biofuels production. Energy Fuel. 29:3111-3118. https://doi. org/10.1021/ef5027373

4. Mulenga D, Siziya S (2019) Indoor air pollution related respiratory ill health, a sequel of biomass use. SciMedicine J. 1(1):30-37. https://doi. org/10.28991/SciMedJ-2019-0101-5

5. Jawaduddin M, Memon SA, Bheel N, Ali F, Ahmed N, Abro AW (2019) Synthetic grey water treatment through FeCl3-activated carbon obtained from cotton stalks and river sand. Civ Eng J. 5(2):340-348. https://doi. org/10.28991/cej-2019-03091249

6. Alzeyadi A, Al-Ansari N, Laue J, Alattabi A (2019) Study of biomass bottom ash efficiency as phosphate sorbent material. Civ Eng J. 5(11):2392-2401. https://doi.org/10.28991/cej-2019-03091419

7. Pan X, Arato C, Gilkes N, Gregg D, Mabee W, Pye K, Xiao Z, Zhang X, Saddler J (2005) Biorefining of softwoods using ethanol organosolv pulping: preliminary evaluation of process streams for manufacture of fuel-grade ethanol and co-products. Biotechnol Bioeng 90(4):473-481. https://doi. org/10.1002/bit.20453

8. Guerriero G, Hausman J-F, Strauss J, Ertan H, Siddiqui KS (2016) Lignocellulosic biomass: biosynthesis, degradation, and industrial utilization. Eng Life Sci 16(1):1-16. https://doi.org/10.1002/elsc.201400196

9. Yang $\mathrm{H}$, Yan $\mathrm{R}$, Chen $\mathrm{H}$, Lee DH, Zheng C (2007) Characteristics of hemicellulose, cellulose and lignin pyrolysis. Fuel 86(12-13):1781-1788. https ://doi.org/10.1016/j.fuel.2006.12.013

10. Luo Y, Li Z, Li X, Liu X, Fan J, Clark JH, Hu C (2019) The production of furfural directly from hemicellulose in lignocellulosic biomass: a review. Catal Today 319:14-24. https://doi.org/10.1016/j.cattod.2018.06.042

11. Chundawat SP, Beckham GT, Himmel ME, Dale BE (2011) Deconstruction of lignocellulosic biomass to fuels and chemicals. Annu Rev Chem Biomol Eng. 2:121-145. https://doi.org/10.1146/annurev-chembioeng $-061010-114205$

12. Ragauskas AJ, Beckham GT, Biddy MJ, Chandra R, Chen F, Davis MF, Davison BH, Dixon RA, Gilna P, Keller M et al (2014) Lignin valorization: improving lignin processing in the biorefinery. Science 344(6185):1246843. https ://doi.org/10.1126/science.1246843

13. Agbor VB, Cicek N, Sparling R, Berlin A, Levin DB (2011) Biomass pretreatment: fundamentals toward application. Biotechnol Adv 6(29):675-685. https://doi.org/10.1016/j.biotechadv.2011.05.005

14. Rinaldi R, Jastrzebski R, Clough MT, Ralph J, Kennema M, Bruijnincx PC, Weckhuysen BM (2016) Paving the way for lignin valorisation: recent advances in bioengineering, biorefining and catalysis. Angewandte Chemie. 55(29):8164-8215. https://doi.org/10.1002/anie.201510351

15. Yan X, Wang Z, Zhang K, Si M, Liu M, Chai L, Liu X, Shi Y (2017) Bacteriaenhanced dilute acid pretreatment of lignocellulosic biomass. Bioresour Technol 245(Pt A):419-425. https://doi.org/10.1016/j.biortech.2017.08.037

16. Si M, Zhang J, He Y, Yang Z, Yan X, Liu M, Zhuo S, Wang S, Min X, Gao C et al (2018) Synchronous and rapid preparation of lignin nanoparticles and carbon quantum dots from natural lignocellulose. Green Chem 20(15):3414-3419. https://doi.org/10.1039/c8gc00744f

17. Liu D, Yan X, Zhuo S, Si M, Liu M, Wang S, Ren L, Chai L, Shi Y: Pandoraea sp B-6 assists the deep eutectic solvent pretreatment of rice straw via promoting lignin depolymerization. Bioresour technol. 2018, 257:62-68. http://doi.org/10.1016/j.biortech.2018.02.029

18. Duval A, Lawoko M (2014) A review on lignin-based polymeric, microand nano-structured materials. React Funct Polym 85:78-96. https://doi. org/10.1016/j.reactfunctpolym.2014.09.017 
19. Nair SS, Sharma S, Pu Y, Sun Q, Pan S, Zhu JY, Deng Y, Ragauskas AJ (2014) High shear homogenization of lignin to nanolignin and thermal stability of nanolignin-polyvinyl alcohol blends. Chemsuschem 7(12):3513-3520. https://doi.org/10.1002/cssc.201402314

20. Qian Y, Deng Y, Qiu X, Li H, Yang D (2014) Formation of uniform colloidal spheres from lignin, a renewable resource recovered from pulping spent liquor. Green Chem 16(4):2156. https://doi.org/10.1039/c3gc42131g

21. Liu ZH, Hao N, Shinde S, Pu Y, Kang X, Ragauskas AJ, Yuan JS (2019) Defining lignin nanoparticle properties through tailored lignin reactivity by sequential organosolv fragmentation approach (SOFA). Green Chem 21(2):245-260. https://doi.org/10.1039/c8gc03290d

22. Tian D, Hu J, Bao J, Chandra RP, Saddler JN, Lu C (2017) Lignin valorization: lignin nanoparticles as high-value bio-additive for multifunctional nanocomposites. Biotechnol Biofuels 10:192. https://doi.org/10.1186/ s13068-017-0876-z

23. Song HT, Gao Y, Yang YM, Xiao WJ, Liu SH, Xia WC, Liu ZL, Yi L, Jiang ZB (2016) Synergistic effect of cellulase and xylanase during hydrolysis of natural lignocellulosic substrates. Bioresour Technol 219:710-715. https:// doi.org/10.1016/j.biortech.2016.08.035

24. Zhuo S, Yan X, Liu D, Si M, Zhang K, Liu M, Peng B, Shi Y (2018) Use of bacteria for improving the lignocellulose biorefinery process: importance of pre-erosion. Biotechnol Biofuels 11:146. https://doi.org/10.1186/s1306 8-018-1146-4

25. Zhuo S, Peng B, Yan X, Zhang K, Si M, Liu M, Shi Y (2018) Conquering lignin recalcitrance by Pandoraea sp B-6 to improve co-solvent pretreatment of corn stover. Process Biochem. 75:187-193. https://doi. org/10.1016/.procbio.2018.09.012

26. Lievonen M, Valle-Delgado JJ, Mattinen M-L, Hult E-L, Lintinen K, Kostiainen MA, Paananen A, Szilvay GR, Setälä H, Österberg M (2016) A simple process for lignin nanoparticle preparation. Green Chem 18(5):14161422. https://doi.org/10.1039/c5gc01436k

27. Dai L, Liu R, Hu L-Q, Zou Z-F, Si C-L (2017) Lignin nanoparticle as a novel green carrier for the efficient delivery of resveratrol. ACS Sustain Chem Eng. 5(9):8241-8249. https://doi.org/10.1021/acssuschemeng.7b01903

28. Zhao W, Simmons B, Singh S, Ragauskas A, Cheng G (2016) From lignin association to nano-/micro-particle preparation: extracting higher value of lignin. Green Chem 18(21):5693-5700. https://doi.org/10.1039/c6gc0 $1813 \mathrm{k}$

29. Si M, Yan X, Liu M, Shi M, Wang Z, Wang S, Zhang J, Gao C, Chai L, Shi Y (2018) In situ lignin bioconversion promotes complete carbohydrate conversion of rice straw by Cupriavidus basilensis B-8. ACS Sustain Chem Eng 6(6):7969-7978. https://doi.org/10.1021/acssuschemeng.8b01336

30. Chai L, Liu M, Yan X, Cheng X, Zhang T, Si M, Min X, Shi Y (2018) Elucidating the interactive impacts of substrate-related properties on lignocellulosic biomass digestibility: a sequential analysis. ACS Sustain Chem Eng. 6(5):6783-6791. https://doi.org/10.1021/acssuschemeng.8b00592

31. Nan Y, Jia L, Yang M, Xin D, Qin Y, Zhang J (2018) Simplified sodium chlorite pretreatment for carbohydrates retention and efficient enzymatic saccharification of silvergrass. Bioresour Technol 261:223-231. https://doi. org/10.1016/j.biortech.2018.03.106

32. Zhang K, Si M, Liu D, Zhuo S, Liu M, Liu H, Yan X, Shi Y (2018) A bionic system with Fenton reaction and bacteria as a model for bioprocessing lignocellulosic biomass. Biotechnol Biofuels 11(1):31. https://doi. org/10.1186/s13068-018-1035-x

33. Yuan TQ, Sun SN, Xu F, Sun RC (2011) Structural characterization of lignin from triploid of Populus tomentosa Carr. J Agric Food Chem 59(12):66056615. https://doi.org/10.1021/jf2003865

34. Janaki S, Punithamurthy K, Renuka L (2019) A Novel approach for synthesis of LaFeO3/Bentonite Nanocomposite for degradation of methylene blue with enhanced photocatalytic activity. Mater Res Express. 6:035013. https://doi.org/10.1088/2053-1591/aaf333

35. Tong-Qi Y, Shaoni S, Feng X, Sun R-C (2011) Isolation and physico-chemical characterization of lignins from ultrasound irradiated fast-growing poplar wood. Bioresource 6:414-433. https://doi.org/10.15376/biore s.6.1.414-433

36. Lang W (2012) High-solids loading enzymatic hydrolysis of waste papers for biofuel production. Appl Energy. 99:23-31. https://doi.org/10.1016/j. apenergy.2012.03.045

37. Si M, Liu D, Liu M, Yan X, Gao C, Chai L, Shi Y (2019) Complementary effect of combined bacterial-chemical pretreatment to promote enzymatic digestibility of lignocellulose biomass. Bioresour Technol 272:275-280. https://doi.org/10.1016/j.biortech.2018.10.036

38. Ooshima H, Burns DS, Converse A (1990) Adsorption of cellulase from trichoderma reesei on cellulose and lignacious residue in wood pretreated by dilute sulfuric acid with explosive decompression. Biotechnol Bioeng 36:446-452. https://doi.org/10.1002/bit.260360503

39. Dong M, Wang S, Xu F, Wang J, Yang N, Li Q, Chen J, Li W (2019) Pretreatment of sweet sorghum straw and its enzymatic digestion: insight into the structural changes and visualization of hydrolysis process. Biotechnol Biofuels 12:276. https://doi.org/10.1186/s13068-019-1613-6

40. Ji Z, Zhang X, Ling Z, Zhou X, Ramaswamy S, Xu F (2015) Visualization of Miscanthus $x$ giganteus cell wall deconstruction subjected to dilute acid pretreatment for enhanced enzymatic digestibility. Biotechnol Biofuels 8:103. https://doi.org/10.1186/s13068-015-0282-3

41. Djajadi DT, Jensen MM, Oliveira M, Jensen A, Thygesen LG, Pinelo M, Glasius M, Jørgensen H, Meyer AS (2018) Lignin from hydrothermally pretreated grass biomass retards enzymatic cellulose degradation by acting as a physical barrier rather than by inducing nonproductive adsorption of enzymes. Biotechnol Biofuels. https://doi.org/10.1186/s13068-018-1085-0

42. Cai CM, Zhang T, Kumar R, Wyman CE (2013) THF co-solvent enhances hydrocarbon fuel precursor yields from lignocellulosic biomass. Green Chem 15(11):3140. https://doi.org/10.1039/c3gc41214h

43. Cai CM, Nagane N, Kumar R, Wyman CE (2014) Coupling metal halides with a co-solvent to produce furfural and 5-HMF at high yields directly from lignocellulosic biomass as an integrated biofuels strategy. Green Chem. 16(8):3819-3829. https://doi.org/10.1039/c4gc00747f

44. Jiang Z, He T, Li J, Hu C (2014) Selective conversion of lignin in corncob residue to monophenols with high yield and selectivity. Green Chem 16(9):4257-4265. https://doi.org/10.1039/c4gc00620h

45. Wu P, Li L, Sun Y, Song B, Yu Y, Liu H (2020) Near complete valorisation of Hybrid pennisetum to biomethane and lignin nanoparticles based on gamma-valerolactone/water pretreatment. Bioresour Technol 305:123040. https://doi.org/10.1016/j.biortech.2020.123040

46. Myint AA, Lee HW, Seo B, Son W-S, Yoon J, Yoon TJ, Park HJ, Yu J, Yoon J, Lee Y-W (2016) One pot synthesis of environmentally friendly lignin nanoparticles with compressed liquid carbon dioxide as an antisolvent. Green Chem 18(7):2129-2146. https://doi.org/10.1039/c5gc02398j

47. Mou H, Li B, Fardim P (2014) Pretreatment of corn stover with the modified hydrotropic method to enhance enzymatic hydrolysis. Energy Fuels. 28(7):4288-4293. https://doi.org/10.1021/ef5001634

48. Tang C, Shan J, Chen Y, Zhong L, Shen T, Zhu C, Ying H (2017) Organic amine catalytic organosolv pretreatment of corn stover for enzymatic saccharification and high-quality lignin. Bioresour Technol 232:222-228. https://doi.org/10.1016/j.biortech.2017.02.041

49. Yang $X$, Ma F, Zeng Y, Yu H, Xu C, Zhang X (2010) Structure alteration of lignin in corn stover degraded by white-rot fungus Irpex lacteus CD2. Inter Biodeter Biodegr. 64(2):119-123. https://doi.org/10.1016/j.ibiod .2009.12.001

50. Demirbaş A (2005) Adsorption of $\mathrm{Cr}(\mathrm{III})$ and $\mathrm{Cr}(\mathrm{VI})$ ions from aqueous solutions on to modified lignin. Energy Sour. 27(15):1449-1455. https:// doi.org/10.1080/009083190523352

51. Yuan TQ, Sun SN, Xu F, Sun RC (2011) Isolation and physico-chemical characterization of lignins from ultrasound irradiated fast-growing poplar wood. Bioresources. 6(1):414-433. https://doi.org/10.15376/biore s.6.1.414-433

52. Trajano H, Engle $H$, Foston $M(2013)$ The fate of lignin during hydrothermal pretreatment. Biotechnol Biofuels 6:110. https://doi. org/10.1186/1754-6834-6-110

53. Pielhop T, Larrazábal GO, Studer MH, Brethauer S, Seidel C-M (2015) Lignin repolymerisation in spruce autohydrolysis pretreatment increases cellulase deactivation. Green Chem 17(6):3521-3532. https://doi.org/10.1039/ c4gc02381a

54. Li S, Li W, Zhang Q, Shu R, Wang H, Xin H, Ma L (2018) Lignin-first depolymerization of native corn stover with an unsupported MoS2 catalyst. RSC Advances. 8(3):1361-1370. https://doi.org/10.1039/c7ra11947j

55. Zhang P, Dong SJ, Ma HH, Zhang BX, Wang YF, Hu XM (2015) Fractionation of corn stover into cellulose, hemicellulose and lignin using a series of ionic liquids. Ind Crop Prod. 76:688-696. https://doi.org/10.1016/j.inder op.2015.07.037 
56. Guo X (2017) Compositional and structural changes of corn cob pretreated by electron beam irradiation. ACS Sustain Chem Eng. 5:420-425. https://doi.org/10.1021/acssuschemeng.6b01793

57. Wen JL, Sun SL, Yuan TQ, Sun RC (2015) Structural elucidation of whole lignin from Eucalyptus based on preswelling and enzymatic hydrolysis. Green Chem 17(3):1589-1596. https://doi.org/10.1039/c4gc01889c

\section{Publisher's Note}

Springer Nature remains neutral with regard to jurisdictional claims in published maps and institutional affiliations.
Ready to submit your research? Choose BMC and benefit from:

- fast, convenient online submission

- thorough peer review by experienced researchers in your field

- rapid publication on acceptance

- support for research data, including large and complex data types

- gold Open Access which fosters wider collaboration and increased citations

- maximum visibility for your research: over 100M website views per year

At BMC, research is always in progress.

Learn more biomedcentral.com/submissions 